\title{
DOSES DE POTÁSSIO NA PRODUÇÃO DA ALFACE
}

Arthur Bernardes Cecílio Filho ${ }^{1}$, Alexsandra Souza Nascimento da Silva ${ }^{2}$, Sandra Maria Cruz Nascimento ${ }^{2}$; Pablo Forlan Vargas ${ }^{3 *}$

\footnotetext{
${ }^{1}$ Docente da Universidade Estadual Paulista (UNESP), Faculdade de Ciências Agrárias e Veterinária, Câmpus de Jaboticabal - SP.

${ }^{2}$ Docente do IFMA - Campus Maracanã, Av. dos Curiós, S/N - Vila Esperança - São Luís - MA.

${ }^{3}$ Docente da Universidade Estadual Paulista (UNESP), Câmpus Experimental de Registro - SP / Universidade Estadual Paulista (UNESP), Centro de Raízes e Amidos Tropicais (CERAT), Botucatu - SP. *E-mail: pablo@ registro.unesp.br, pfvargas@cerat.unesp.br
}

RESUMO: A utilização de fertilizantes minerais em alface é uma prática agrícola que traz resultados satisfatórios, porém, é necessário saber qual dose ótima de acordo com cada tipo de solo. Desta forma, objetivou com este trabalho avaliar a influência de doses de potássio (K) sobre o crescimento e produção de alface 'Vera', em um solo contendo baixos teores de $\mathrm{K}\left(0,3 \mathrm{mmol}_{\mathrm{c}} \mathrm{dm}^{-3}\right)$. O experimento foi realizado de 3 de setembro de 2011 a 4 de janeiro, de 2012, em blocos casualizados com seis tratamentos $\left(0,50,100,150,200\right.$ e $250 \mathrm{~kg} \mathrm{ha}^{-1} \mathrm{de}$ $\mathrm{K}_{2} \mathrm{O}$ ) e quatro repetições. A alface foi colhida 45 dias após o transplante das mudas. Foram verificados efeitos significativos na massa fresca e seca da parte aérea, teor de $\mathrm{K}$ no solo e acúmulo de $\mathrm{K}$ na planta, os quais foram maximizados com as doses de 180, 153, 250 e 250 $\mathrm{kg} \mathrm{ha}^{-1}$ de $\mathrm{K}_{2} \mathrm{O}$, respectivamente. Não houve diferença significativa para o teor foliar de $\mathrm{K}$ nas doses de $\mathrm{K}_{2} \mathrm{O}$ avaliadas. Em Argissolo Vermelho Amarelo distrocoeso, com baixa disponibilidade de potássio, a alface responde positivamente a adubação potássica, sendo necessários $180 \mathrm{~kg} \mathrm{ha}^{-1}$ de $\mathrm{K}_{2} \mathrm{O}$.

Palavras-chave: Lactuca sativa. Dose econômica. Produtividade.

\section{DOSES OF POTASSIUM IN PRODUCTION OF LETTUCE}

\begin{abstract}
The use of mineral fertilizers in lettuce is a farming practice that brings satisfactory results, however, it is necessary to know that the optimal dose according to each soil type. Given the above, the objective was evaluate potassium levels in lettuce 'Vera' to growing and yield in a low levels potassium in soil. The experiment was conducted between September 3, 2011 to January 4, 2012 in a randomized complete block design with six treatments $\left(0,50,100,150,200\right.$ e $250 \mathrm{~kg} \mathrm{ha}^{-1}$ de $\left.\mathrm{K}_{2} \mathrm{O}\right)$ and four replications. Plants were harvested 45 days after transplanting. Potassium fertilization resulted in significant response in fresh and dry mass, $\mathrm{K}$ content in the soil and accumulation of $\mathrm{K}$ in the aerial part, which were maximized with doses of $180,153,250$ and $250 \mathrm{~kg} \mathrm{ha}^{-1}$ de $\mathrm{K}_{2} \mathrm{O}$, respectively. In Ultisol, with low available potassium, lettuce responds positively to potassium fertilization, requiring $180 \mathrm{~kg} \mathrm{ha}^{-1}$ of $\mathrm{K}_{2} \mathrm{O}$.
\end{abstract}


Key words: Lactuca sativa. Economical dose. Productivity.

\section{INTRODUÇÃO}

A alface é a hortaliça folhosa mais cultivada e consumida no país, sendo produzida em todos os estados da federação e, por suas características de produção, há necessidade de uma intensa mão-de-obra para realizar os tratos culturais necessários. Desta forma, a alfacicultura têm um grande impacto socioeconómico nas regiões produtoras (MARCHI et al., 2015), devido a mão-de-obra empregada.

Entre os muitos fatores a serem estudados no sistema de produção da alface, tem-se a fertilização da cultura, pois este aspecto afeta o seu crescimento, a produção e a qualidade do produto colhido (CHICONATO et al., 2014). A alface é uma cultura altamente dependente de fertilizantes e, a aplicação de doses corretas, com base nos teores dos elementos no solo, é de fundamental importância tanto para a viabilidade econômica do cultivo quanto para a mitigação dos impactos negativos que essa ação causa ao ambiente.

Dentre os nutrientes mais exigidos pela cultura, destaca-se o potássio, segundo nutriente mais requerido pelas hortaliças, atrás somente do nitrogênio, o qual desempenha diversas funções metabólicas e de crescimento (CANCELLIER et al., 2010).

O potássio $(\mathrm{K})$, macronutriente mais acumulado pela alface (GRANGEIRO et al., 2006), exerce influência direta na formação da cabeça (KANO, CARDOSO e VILAS BOAS, 2010), e em geral é encontrado com teores insuficientes em solos brasileiros (OTTO, VITTI e LUZ, 2010). Esse nutriente participa direta e indiretamente de inúmeros processos bioquímicos envolvidos com o metabolismo dos carboidratos, a fotossíntese e respiração (COSTA et al., 2009).

A absorção de $\mathrm{K}$ e sua translocação nas plantas são fortemente afetados pela disponibilidade de $\mathrm{K}$ no solo (LUO, HE e LEE, 2012). As plantas apresentaram menor concentração de $\mathrm{K}$ nas folhas quando cultivadas em meio inferior $\mathrm{K}$ em comparação com as plantas cultivadas em meio de maior concentração de K. A disponibilidade de um elemento para a planta, bem como, a capacidade de seu suprimento pelo solo é dependente, dentre vários fatores, da fertilização (WERLE et al., 2008).

O potássio trocável e o potássio na solução são as fontes imediatas do nutriente para a cultura (CURI, KAMPF e MARQUES, 2004), contudo a passagem do K da forma trocável para a não trocável ocorre de forma rápida, dependendo da sua concentração na solução do solo (ROSOLEM et al., 2006). Há também a perda de elementos por lixiviação, através de irrigações mal realizadas ou excesso de precipitação, nesse contexto, há um intenso deslocamento de bases trocáveis $(\mathrm{K}, \mathrm{Ca}$ e $\mathrm{Mg}$ ), tendo como consequência a redução da CTC e aumento da acidez (CARMO et al., 2010).

Em estudo para avaliação nutricional da alface, Almeida et al. (2011) verificaram em cultivo em solução nutritiva completa e em deficiência de K, valores de 1.313,53 e 102,33 
$\mathrm{mm}^{2}$, para área foliar; 26 e 15, para número de folhas; 7,17 e 0,10 $\mathrm{g} \mathrm{planta}^{-1}$, para massa seca da parte aérea; 1,2 e 0,10 g planta $^{-1}$, para massa seca de raízes e 8,19 e 0,15 g planta ${ }^{1}$,para a massa da planta inteira, respectivamente.

Já Tosta et al. (2009), avaliando adubação potássica (150, 300 e $\left.450 \mathrm{~kg} \mathrm{ha}^{-1}\right)$ em alface, observaram influência significativa da adubação sobre a massa da planta, número de folhas e produtividade. A máxima massa da cabeça foi de $926,6 \mathrm{~g}$, perfazendo um produtividade de 56,6 $\mathrm{t} \mathrm{ha}^{-1}$, com $300 \mathrm{~kg} \mathrm{ha}^{-1}$ de $\mathrm{K}_{2} \mathrm{O}$. Já para o número de folhas, a adubação que maximizou essa característica foi de $336 \mathrm{~kg} \mathrm{ha}^{-1}$.

A grande importância do K para a cultura da alface é relatada por Petrazzini et al. (2014), que em estudos realizados verificaram que o $\mathrm{K}$ foi o nutriente que mais restringiu a produção de matéria fresca, matéria seca de parte aérea e matéria seca de raiz.

Considerando a hipótese de que em um Argissolo Vermelho Amarelo distrocoeso com baixo teor de potássio há incrementos na produção de alface crespa com o fornecimento deste elemento, objetivou com o presente estudo avaliar doses de potássio na nutrição e desempenho da alface em solo com baixo teor de potássio.

\section{MATERIAL E MÉTODOS}

O experimento foi realizado no período de 3 de setembro de 2011 a 4 de janeiro de 2012, no Campus Maracanã - IFMA - São Luis, situado a 2³6’35,94’' de Latitude Sul, $44^{\circ} 15^{\prime} 52,02^{\prime}$ ' Longitude Oeste, e altitude de 34 metros.

O clima da região, segundo a classificação de Thornthwaite, é do tipo B1 WA, caracterizado como úmido, com moderada deficiência de água no inverno, entre os meses de junho a setembro. A temperatura média anual é de $27^{\circ} \mathrm{C}$, com precipitação pluvial média anual de $2000 \mathrm{~mm}$. O solo onde se realizou o cultivo é um Argissolo Vermelho Amarelo distrocoeso (EMBRAPA, 2013).

As características físico-químicas foram aferidas previamente a instalação do estudo, através de amostras do solo coletadas na camada de 0 a $20 \mathrm{~cm}$. Essas foram enviando ao Laboratório de Química e Fertilidade do Solo da Universidade Estadual do Maranhão.

A análise apresentou uma textura do solo com 6\%, $8 \%$ e $86 \%$ de argila, silte e areia, respectivamente. Já a análise química apresentou: $\mathrm{pH}(\mathrm{CaCl})$ de 4,8; Matéria orgânica de $14 \mathrm{~g} \mathrm{dm}^{-3} ; \mathrm{P}$ (resina) de $14 \mathrm{~g} \mathrm{dm}^{-3} ; \mathrm{K}, \mathrm{Ca}, \mathrm{Mg}, \mathrm{Al}+\mathrm{H}$ e CTC foram, respectivamente, de 0,3, $3,0,4,0,24,0,31,7 \mathrm{mmol}_{\mathrm{c}} \mathrm{dm}^{-3}$ e saturação de base era de $24 \%$.

Com base nos resultados da análise de solo foi realizada calagem, utilizando-se calcário com PRNT de 98\% (32\% de $\mathrm{CaO}$ e 15\% de $\mathrm{MgO}$ ), 30 dias de antecedência, para elevar a saturação por bases do solo a 80\% (TRANI, PASSOS e AZEVEDO FILHO, 1997). Em seguida foi realizada aração e gradagem para incorporação do corretivo. Após o período de reação, foram preparados os canteiros com auxílio de rotoencanteiradora contendo 1,0 m de largura e $0,2 \mathrm{~m}$ de altura. 
A adubação foi realizada de acordo com a recomendação de Trani et al. (1997), exceto para K. O solo dos canteiros recebeu, três dias antes do transplante das mudas, $60 \mathrm{t} \mathrm{ha}^{-1} \mathrm{de}$ esterco bovino curtido, que de acordo com Berton (1997) possui $21 \mathrm{~g} \mathrm{~kg}^{-1} \mathrm{de} \mathrm{K}$, e $40 \mathrm{~kg} \mathrm{ha}^{-1}$ de $\mathrm{N}$, na forma de ureia e $400 \mathrm{~kg} \mathrm{ha}^{-1} \mathrm{de}_{2} \mathrm{O}_{5}$ na forma de superfosfato simples.

$\mathrm{O}$ experimento foi instalado em delineamento de blocos casualizados, com seis tratamentos $\left(0,50,100,150,200\right.$ e $\left.250 \mathrm{~kg} \mathrm{ha}^{-1} \mathrm{de}_{2} \mathrm{O}\right)$ com quatro repetições. As parcelas tiveram $3,0 \mathrm{~m}$ de comprimento por 1,0 $\mathrm{m}$ de largura, em canteiros contendo quatro linhas de alface, espaçadas em $0,25 \times 0,25 \mathrm{~m}$, totalizando 48 plantas. Foram consideradas como área útil da parcela, para coleta dos dados, as oito plantas centrais das duas linhas centrais da parcela.

Foi utilizada a cv. Vera ${ }^{\circledR}$, do grupo Crespa, escolhida por sua boa aceitação no mercado local, e pelos bons resultados obtidos em testes de avaliação de cultivares na região.

As mudas foram produzidas no viveiro do Setor de Agricultura I do Instituto Federal do Maranhão, Campus Maracanã, em São Luís, MA, em bandejas de polipropileno com 128 células, preenchidas com o substrato comercial Plantmax HA ${ }^{\circledR}$. A semeadura foi realizada colocando-se duas sementes peletizadas por célula. Após a semeadura, as bandejas foram cobertas com uma fina camada do próprio substrato. Sete dias após a emergência das plântulas, foi realizado o desbaste, deixando-se uma planta por célula. O suprimento de água no período de viveiro foi efetuado duas vezes ao dia. O transplante para o local definitivo foi realizado quando as mudas apresentaram quatro folhas completas, 21 dias após a semeadura.

Em cobertura, foram aplicados $90 \mathrm{~kg} \mathrm{ha}^{-1}$ de $\mathrm{N}$ na forma de ureia, parcelado aos 10, 20 e 30 dias após o transplante (DAT). Semanalmente, as plantas foram pulverizadas com nitrato de cálcio, com $2,5 \mathrm{~g} \mathrm{~L}^{-1}$ e $400 \mathrm{~L} \mathrm{ha}^{-1}$ de calda.

A irrigação foi realizada via sistema localizado, através de tubogotejador, sendo um tubo gotejador para cada duas linhas de plantas, e os gotejadores espaçados em $0,30 \times 0,30$ $\mathrm{m}$, de acordo com a necessidade da cultura.

O controle das plantas daninhas foi realizado semanalmente, pelo método manual. Não foi constatada a ocorrência de problemas fitossanitários ao longo do cultivo, não havendo necessidade de intervenção.

Foi avaliado durante o ciclo da cultura o (a) teor foliar de K: quando as plantas atingiram, aproximadamente, dois terços do ciclo estimado, foi realizada a amostragem de folhas recém desenvolvidas, segundo a recomendação de Trani e Raij (1997), para avaliação do estado nutricional. A coleta foi realizada logo no início do dia entre as seis e sete horas da manhã. Após coletadas, as folhas foram levadas ao Laboratório e lavadas com água corrente e em água deionizada. Após a remoção do excesso de água com papel toalha, as amostras foram colocadas em sacos de papel, identificadas e levadas para secagem em estufa com circulação forçada de ar, a $65^{\circ} \mathrm{C}$, até atingirem massa constante. Em seguida,

Cultura Agronômica, Ilha Solteira, v.27, n.2, p.217-227, 2018 
cada amostra foi moída no moinho tipo Wiley. O preparo do extrato para leitura do teor de K realizado conforme Bataglia et al. (1983).

Realizou-se a colheita aos 45 dias após o transplante quando as plantas apresentavamse completamente desenvolvidas em sua parte vegetativa.

Após a colheita foram avaliadas as seguintes características:

(b) Massa fresca da parte aérea (MFPA): realizou-se o corte do caule rente a superfície do solo. As folhas mortas e senescentes foram descartadas e a massa determinada com o auxílio de uma balança eletrônica Toledo ${ }^{\circledR}$ modelo PS 4500 de precisão $(0,01 \mathrm{~g})$.

(c) Massa seca da parte aérea (MSPA): a parte aérea das plantas avaliadas foram secas em estufa com circulação forçada, a $65^{\circ} \mathrm{C}$, até atingirem massa constante. Após a secagem, foi realizado aferição da massa seca por meio de uma balança eletrônica Toledo ${ }^{\circledR}$ modelo PS 4500 de precisão $(0,01 \mathrm{~g})$.

(d) Teor de K no solo: após o término do experimento, foram coletadas amostras de solo de cada parcela, na camada de 0 a $20 \mathrm{~cm}$, para determinação dos teores de $\mathrm{K}$ disponível. Previamente a amostragem, foi realizada a homogeneização do leito da parcela e em seguida coletadas oito amostras simples para compor uma amostra composta por parcela. As amostras foram peneiradas e colocadas para secar a sombra. Em seguida foram levadas para o laboratório de Solos, da UEMA, para determinação do teor do nutriente, segundo a metodologia descrita por Raij et al. (2001).

(e) Acúmulo de $\mathrm{K}$ (mg planta $^{-1}$ ): obtido pelo produto entre o teor de $\mathrm{K}$ na MSPA e a quantidades acumuladas de MSPA.

Com os dados médio das características avaliadas, foi realizada a análise de variância (teste F), segundo o delineamento proposto, e a análise de regressão polinomial, optando pela equação de maior ajuste significativo. Foi utilizado o programa estatístico AGROESTAT, desenvolvido pelo Departamento de Ciências Exatas, da Faculdade de Ciências Agrárias e Veterinárias da Unesp, Campus de Jaboticabal. Os gráficos foram gerados no programa Microsoft Excel.

\section{RESULTADOS E DISCUSSÃO}

O teor de K no solo foi influenciado pelo aumento das doses de K (Tabela 1) e houve ajuste de equação linear às médias observadas (Figura 1).

Embora os teores de $\mathrm{K}$ no solo aumentaram proporcionalmente com o incremento na quantidade aplicada do nutriente, elevando o teor para $1,45 \mathrm{mmol}_{\mathrm{c}} \mathrm{dm}^{-3} \mathrm{com}$ a maior dose aplicada (Tabela 1), cerca de cinco vezes maior do que o teor antes da fertilização, todos os teores observados ao final do estudo situaram-se na faixa considerada de teores baixos para hortaliças (RAIJ et al., 1997).

$\mathrm{O}$ pequeno incremento no teor de $\mathrm{K}$ no solo $\left(0,682 \mathrm{mmol}_{\mathrm{c}} \mathrm{dm}^{-3}\right)$, mediante as doses de até $250 \mathrm{~kg} \mathrm{ha}^{-1}$ de $\mathrm{K}_{2} \mathrm{O}$ (Figura 1), pode ser explicado pela alta demanda do nutriente pela 
alface, sendo este o elemento acumulado em maior quantidade, conforme observaram Beninni, Takahashi e Neves (2005) e Grangeiro et al. (2006).

Tabela 1. Análise de variância, médias e valores de regressão polinomial para teor de K no solo (KS), teor de $\mathrm{K}$ na folha $(\mathrm{KF})$, massa fresca e (MFPA) massa seca da parte aérea (MSPA) e acúmulo de $\mathrm{K}$ ( $\mathrm{K}$ acumulado) em plantas de alfaces 'Vera' cultivada em Argissolo Amarelo distrocoeso com baixa disponibilidade de potássio em função de doses de potássio.

\begin{tabular}{|c|c|c|c|c|c|}
\hline $\begin{array}{l}\text { Fonte de } \\
\text { variação }\end{array}$ & $\begin{array}{c}\text { K no solo } \\
\left(\mathrm{mmol}_{\mathrm{c}} \mathrm{dm}^{-3}\right)\end{array}$ & $\begin{array}{c}\text { K na folha } \\
\left(\mathrm{g} \mathrm{kg}^{-1}\right)\end{array}$ & $\begin{array}{c}\text { MFPA } \\
\left(\mathrm{g} \mathrm{planta}^{-1}\right)\end{array}$ & $\begin{array}{c}\text { MSPA } \\
\left(\mathrm{g} \mathrm{planta}^{-1}\right)\end{array}$ & $\begin{array}{c}\text { K acumulado } \\
\left(\mathrm{mg} \mathrm{planta}^{-1}\right)\end{array}$ \\
\hline \multirow{2}{*}{ Tratamentos } & \multicolumn{5}{|c|}{ Valores de F } \\
\hline & $5,51 * *$ & $1,22^{\mathrm{NS}}$ & $8,11 * *$ & $7,24 * *$ & $5,51 * *$ \\
\hline $\mathrm{kg} \mathrm{ha}^{-1} \mathrm{de}_{2} \mathrm{O}$ & \multicolumn{5}{|c|}{ Médias } \\
\hline 0 & 0,75 & 16,04 & 57,80 & 3,70 & 96,83 \\
\hline 50 & 0,70 & 24,42 & 113,00 & 7,10 & 237,94 \\
\hline 100 & 0,70 & 22,37 & 134,30 & 7,27 & 257,36 \\
\hline 150 & 1,02 & 18,67 & 162,30 & 8,90 & 375,62 \\
\hline 200 & 1,22 & 26,65 & 162,50 & 7,50 & 300,76 \\
\hline 250 & 1,45 & 21,85 & 150,80 & 6,85 & 346,20 \\
\hline \multicolumn{6}{|l|}{ Regressão } \\
\hline $1^{\circ}$ grau & $24,14 * *$ & $1,21^{\mathrm{NS}}$ & $25,55^{* *}$ & $11,96^{* *}$ & $9,01 * *$ \\
\hline $2^{\circ}$ grau & $0,70^{\mathrm{NS}}$ & $0,65^{\mathrm{NS}}$ & $11,28 * *$ & $20,57 * *$ & $3,74^{\mathrm{NS}}$ \\
\hline $3^{\circ}$ grau & $0,98^{\mathrm{NS}}$ & $0,36^{\mathrm{NS}}$ & $0,61^{\mathrm{NS}}$ & $0,59^{\mathrm{NS}}$ & $1,97^{\mathrm{NS}}$ \\
\hline C.V.(\%) & 27,40 & 32,06 & 20,72 & 18,55 & 27,60 \\
\hline
\end{tabular}

** significativo para $p<0,01 \mathrm{e}^{\mathrm{ns}}$ não significativo para $p>0,05$ pelo teste $\mathrm{F}$.

Bonela (2010), em solo com alto teor de K no solo, também encontrou ajuste linear para as médias de $\mathrm{K}$ no solo em função do aumento no fornecimento do nutriente. Também ao final do estudo observou que, para cada aumento de $50 \mathrm{~kg} \mathrm{ha}^{-1} \mathrm{de}_{2} \mathrm{O}$, no intervalo de zero a $100 \mathrm{~kg} \mathrm{ha}^{-1}$ de $\mathrm{K}_{2} \mathrm{O}$, houve incremento de $0,2 \mathrm{mmol}_{\mathrm{c}} \mathrm{dm}^{-3}$ de $\mathrm{K}$, enquanto no presente trabalho houve incremento de $0,14 \mathrm{mmol}_{\mathrm{c}} \mathrm{dm}^{-3}$ de $\mathrm{K}$, no solo, no intervalo de zero a $250 \mathrm{~kg}$ $\mathrm{ha}^{-1}$ de $\mathrm{K}_{2} \mathrm{O}$ (Figura 1).

Bonela (2010) observou que mesmo no solo com alto teor de $\mathrm{K}\left(3,4 \mathrm{mmol}_{\mathrm{c}} \mathrm{dm}^{-3}\right)$ e fertilizado com doses de até $100 \mathrm{~kg} \mathrm{ha}^{-1}$ de $\mathrm{K}_{2} \mathrm{O}$, após a colheita da alface, os teores de $\mathrm{K}$ no solo foram menores do que o teor inicial.

Quanto ao teor foliar de K, este não foi influenciado significativamente pelo aumento no fornecimento de K (Tabela 1). Também, não foi constatado ajuste significativo de equação polinomial para as médias observadas. $\mathrm{O}$ teor médio foi de $21,7 \mathrm{~g} \mathrm{~kg}^{-1}$, aquém do adequado para alface, que segundo Trani e Raij (1997) deve estar entre 50 e $80 \mathrm{~g} \mathrm{~kg}^{-1}$. Entretanto, mesmo apresentando teores de $\mathrm{K}$ abaixo do considerado ideal, não foram observados sintomas visuais da carência do nutriente nas plantas. Bonela (2010), avaliando

Cultura Agronômica, Ilha Solteira, v.27, n.2, p.217-227, 2018 
doses de $\mathrm{K}$ em cultivares de alface dos grupos crespa, lisa e americana, em Latossolo com alto teor de $\mathrm{K}$, não observou efeito de dose no teor foliar de $\mathrm{K}$. O autor, entretanto, verificou teores foliares mais altos, de 63,2, 64,9 e 79,6 $\mathrm{g} \mathrm{kg}^{-1}$ de $\mathrm{K}$ foliar para alfaces dos grupos crespa, lisa e americana, respectivamente. Por outro lado, Furtado (2001) e Yuri et al. (2004) encontraram teores mais baixos próximos aos observados no presente trabalho, 29,8 $\mathrm{g} \mathrm{kg}^{-1}$ e $31,2 \mathrm{~g} \mathrm{~kg}^{-1}$, respectivamente.

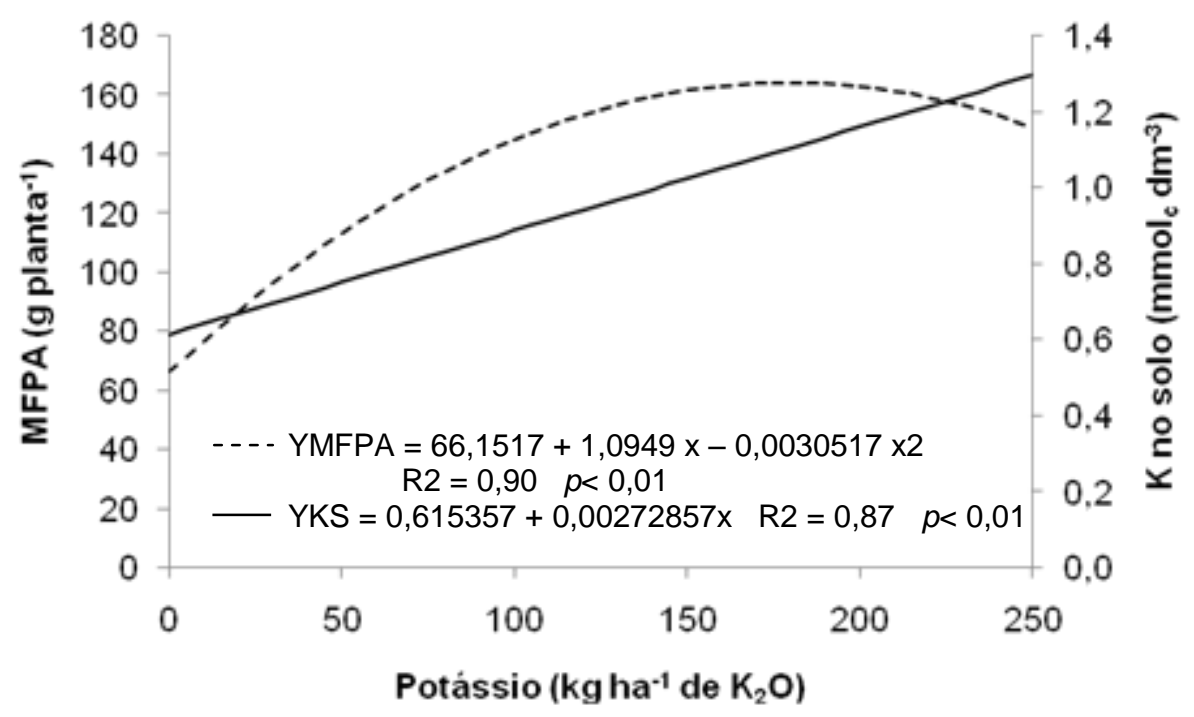

Figura 1. Matéria fresca da parte aérea $\left(\mathrm{Y}_{\mathrm{MFPA}}\right)$ e teor de potássio no solo ( $\left.\mathrm{Y}_{\mathrm{KS}}\right)$ em plantas de alfaces 'Vera' cultivada em Argissolo Amarelo distrocoeso com baixa disponibilidade de potássio em função de doses de potássio.

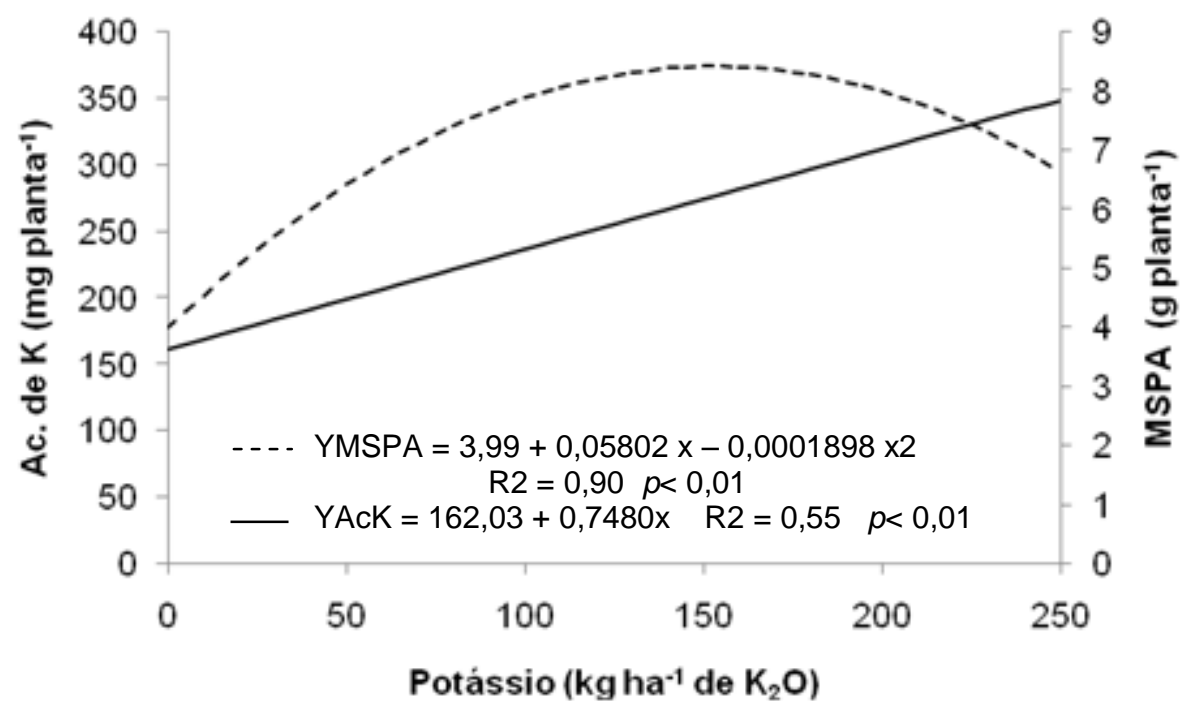

Figura 2. Matéria seca da parte aérea ( $\left.\mathrm{Y}_{\mathrm{MSPA}}\right)$ e acúmulo de $\mathrm{K}\left(\mathrm{Y}_{\mathrm{ac}}\right.$ de $\mathrm{K}$ ) na planta de alface 'Vera' cultivada em Argissolo Amarelo distrocoeso com baixa disponibilidade de potássio em função de doses de potássio. 
Para massa fresca (MFPA) e seca (MSPA) da parte aérea da alface, houve efeito significativo das doses de K. As médias de MFPA e MSPA ajustaram-se a equação polinomial quadrática (Tabela 1, Figuras 1 e 2).

As doses que maximizaram a MFPA $\left(164 \mathrm{~g}\right.$ planta $\left.^{-1}\right)$ (Figura 1) e a MSPA $(8,42 \mathrm{~g}$ planta $^{-1}$ ) (Figura 2) foram 180 e $153 \mathrm{~kg} \mathrm{ha}^{-1} \mathrm{de} \mathrm{K}_{2} \mathrm{O}$. Sem adubação potássica, as MFPA e MSPA foram equivalentes a 40 e $47 \%$, respectivamente, das máximas obtidas. Portanto, o resultado obtido está de acordo com Raij (2011), o qual explica que a resposta à adubação potássica pelas culturas é especialmente acentuada em solos arenosos e de baixa fertilidade. Resultados positivos da adubação potássica em alface também foram constatados por Mota et al. (2003) e Koetz et al. (2006), quando cultivados em solos com baixo ou médio teor de $\mathrm{K}$.

A MFPA obtida no presente estudo é considerada comercial, pois tem massa superior a $100 \mathrm{~g} \mathrm{planta}^{-1}$ (KANO, CARDOSO e VILAS BOAS, 2012). Entretanto, a MFPA foi inferior à obtida por Tosta et al. (2009), que também observaram ajuste quadrático da massa da alface 'Julia' às doses de $\mathrm{K}$, com máxima massa de $693 \mathrm{~g}$ planta $^{-1}$, obtida com $293 \mathrm{~kg}$ ha' ${ }^{1}$ de $\mathrm{K}_{2} \mathrm{O}$, e por Bonela (2010), que obteve média de $312 \mathrm{~g} \mathrm{planta}^{-1} \mathrm{da} \mathrm{cv}$. Amanda, também do grupo crespa, porém em solo contendo alto teor de $\mathrm{K}$.

A massa seca de parte aérea (MSPA) da cv. Vera foi inferior às obtidas para cultivares de alface crespa por Costa et al. (2007), 16,61 $\mathrm{g} \mathrm{planta}^{-1}$ para 'Vera' e por Tosta et al. (2009), 16,20 g planta ${ }^{-1}$ para 'Hortência'. Essa diferente de comportamento, para MFPA e MSPA, pode ser explicada pelo genótipo utilizado e condições edafoclimáticas distintas entre os locais do estudo.

Observou-se ajuste linear as médias de acúmulo de potássio (Tabela 1) ou seja, quanto maior a dose, maior a quantidade acumulada de $\mathrm{K}$ na planta (Figura 2), até a maior dose estuda ( $250 \mathrm{~kg} \mathrm{ha}^{-1}$ de $\left.\mathrm{K}_{2} \mathrm{O}\right)$.

Na dose de $180 \mathrm{~kg} \mathrm{ha}^{-1}$ de $\mathrm{K}_{2} \mathrm{O}$, que maximizou a MFPA, a alface acumulou $268 \mathrm{mg}$ de $\mathrm{K}$, que equivale a $28,3 \mathrm{~kg} \mathrm{ha}^{-1}$ de $\mathrm{K}\left(68,2 \mathrm{~kg} \mathrm{ha}^{-1}\right.$ de $\left.\mathrm{K}_{2} \mathrm{O}\right)$, considerando a população de 105.600 plantas por hectare.

\section{CONCLUSÃO}

Em Argissolo Vermelho Amarelo distrocoeso, com baixa disponibilidade de potássio, o aumento na dose de potássio proporcionou incremento na massa fresca de alface, com a máxima obtida com $180 \mathrm{~kg} \mathrm{ha}^{-1} \mathrm{de}_{2} \mathrm{O}$. 


\section{REFERÊNCIAS BIBLIOGRÁFICAS}

ALMEIDA, T. B. F.; PRADO, R. M.; CORREIA, M. A. R.; PUGA, A. P.; BARBOSA, J. C. Avaliação nutricional de alface cultivada em soluções nutritivas suprimidas de macronutrientes. Revista Biotemas, Florianóplis, v. 24, n. 2, p.27-36, 2011.

BATAGLIA, O. C.; FURLANI, A. C. M.; TEIXEIRA, J. P. F.; FURLANI, P. R.; GALLO, J. R. Métodos de análise química de plantas. Campinas: Instituto Agronômico, 1983. 48 p.

BERTON, R. S. Adubação Orgânica. In: RAIJ, B. VAN.; CANTARELLA, H.; QUAGGIO, J. A.; FURLANI, A. M. C. (Eds.). Recomendações de adubação e calagem para o estado de São Paulo. Campinas: IAC, 1997. cap. 10, p. 30-35.

BENINNI, E. R. Y.; TAKAHASHI, H. W.; NEVES, C. S. V. J. Concentração e acúmulo de macronutrientes em alface cultivadas em sistema hidropônico e convencional. Semina: Ciências Agrárias, Londrina, v. 26, n. 3, p.273-282, 2005.

BONELA, G. D. Adubação fosfatada e potássica para alface em Latossolo com teores altos de p e k disponíveis. 2010. 69 f. Dissertação (Mestrado em Agronomia) - Faculdade de Ciências Agrárias e Veterinárias, Universidade Estadual Paulista, Jaboticabal, 2010.

CANCELLIER, L. L.; ADORIAN, G. C.; RODRIGUES, H. V. M.; SIEBENEICHLER, S. C. LEAL, T. C. A. B. Doses de potássio nas respostas morfofisiológicas de alface. Revista Caatinga, Mossoró, v. 23, n. 4, p.21-27, 2010.

CARMO, S. B. do; FERNANDES, A. R.; NOTONHA, N. C.; SAMPAIO, F. A. R. Características químicas de um Argissolo sob diferentes usos em Ji-Paranã / RO. Amazonian Journal, Belém, v. 53, n. 2, p.143-149, 2010.

CHICONATO, D. A.; GALBIATTI, J. A.; MALDONADO JUNIOR, W.; FRANCO, C. F.; CARAMELO, A. D. Bovine biofertilizer and irrigation layers on lettuce development and leaf chlorophyll. Comunicata Scientiae, Bom Jesus, v. 5, n. 2, p.140-147, 2014.

COSTA, C. C.; CECÍlIO FILHO, A. B.; REZENDE, B. L. A.; BARBOSA, J. C.; GRANGEIRO, L. C. Viabilidade agronômica do consórcio de alface e rúcula, em duas épocas de cultivo. Horticultura Brasileira, Brasília, v. 25, n. 1, p.34-40, 2007.

COSTA, J. P. V.; BARROS, N. F.; BASTOS, A. L.; ALBUQUERQUE, A. W. Fluxo difusivo de potássio em solos sob diferentes níveis de umidade e de compactação. Revista Brasileira de Engenharia Agrícola e Ambiental, Campina Grande, v. 13, n. 1, p.56-62, 2009.

CURI, N.; KAMPF, N.; MARQUES, J. J. Mineralogia e formas de potássio em solos brasileiros. In: YAMADA, T.; ROBERTS, T. L. Potássio na agricultura brasileira. Piracicaba: Associação Brasileira para a Pesquisa da Potassa e do Fósforo, 2004. cap. 4, p. 71-86.

Cultura Agronômica, Ilha Solteira, v.27, n.2, p.217-227, 2018 
EMPRESA BRASILEIRA DE PESQUISA AGROPECUÁRIA - EMBRAPA. Sistema brasileiro de classificação de solos. 3.ed. Brasília: EMBRAPA, 2013. 353 p.

FURTADO, S. C. Nitrogênio e fósforo na produtividade e nutrição mineral de alface americana cultivada em sucessão ao feijão após o pousio da área. 2001. $78 \mathrm{f}$. Dissertação (Mestrado em Fitotecnia) - Universidade Federal de Lavras, Lavras, 2001.

GRANGEIRO, L. C.; COSTA, K. R.; MEDEIROS, M. A.; SALVIANO. A. M.; NEGREIROS, M. Z.; BEZERRA NETO, F. OLIVEIRA, S. L. Acúmulo de nutrientes por três cultivares de alface cultivadas em condições do Semi-Árido. Horticultura Brasileira, Brasília, v. 24, n. 2, p.190-194, 2006.

KANO, C.; CARDOSO, A. I. I.; VILAS BOAS, R. S. Influência de doses de potássio nos teores de macronutrientes em plantas e sementes de alface. Horticultura Brasileira, Brasília, v. 28, n. 3, p.287-291, 2010.

KANO, C.; CARDOSO, A. I. I.; VILLAS BÔAS, R. L. Acúmulo de nutrientes e resposta da alface à adubação fosfatada. Revista Biotemas, Florianópolis, v. 25, n. 3, p.39-47, 2012.

KOETZ, M.; COELHO, G.; CARVALHO, J. A.; SOUZA, R. J.; SILVA, R. A. Produção do meloeiro em ambiente protegido irrigado com diferentes lâminas de água. Irriga, Botucatu, v. 11, n. 4, p.500-506, 2006.

LUO, H. Y.; HE, J.; LEE, S. K. Interaction between potassium concentration and root-zone temperature on growth and photosynthesis of temperate lettuce grown in the tropics. Journal of Plant Nutrition, Philadelphia, v. 35, n. 7, p.1004-1021, 2012.

MARCHI, E. C. S.; MARCHI, G.; SILVA, C. A.; AlVARENGA, M. A. R. Crisphead lettuce under influence of soil conditioner, organic fertilizers and liming. Comunicata Scientiae, Bom Jesus, v. 6, n. 3, p.274-281, 2015.

MOTA, J. H.; YURI, J. E.; RESENDE, G. M.; OLIVEIRA, C. M.; SOUZA, R. J.; FREITAS, S. A. C.; RODRIGUES JÚNIOR, J. C. Produção de alface americana em função da aplicação de doses e fontes de fósforo. Horticultura Brasileira, Brasília, v. 21, n. 4, p.620-622, 2003.

NACHTIGALL, G. R.; VAHL, L. C. Capacidade de suprimento de potássio dos solos da região do Rio Grande do Sul. Revista Brasileira de Ciência do Solo, Viçosa, v. 15, n. 1, p.37-42, 1991.

OTTO, R.; VITTI, G. C.; LUZ, P. H. C. Manejo da adubação potássica na cultura da canade-açúcar. Revista Brasileira de Ciência do Solo, Viçosa, v. 34, n. 4, p.1137-1146, 2010.

PETRAZZINI, L. L.; SOUZA, G. A; RODAS, C. L.; EMRICH, E. B.; CARVALHO, J. G.; SOUZA, R. J. Deficiências de nutrientes em alface americana cultivada em hidroponia. Horticultura Brasileira, Brasília, v. 32, n. 3, p.310-313, 2014.

RAIJ, B. VAN. Fertilidade do solo e adubação. Piracicaba: Potafós, 1991. 343 p.

Cultura Agronômica, Ilha Solteira, v.27, n.2, p.217-227, 2018 
RAIJ, B. VAN. Fertilidade do solo e manejo de nutrientes. 2.ed. Piracicaba, International Plant Nutrition Institute, 2011. 420 p.

RAIJ, B. VAN.; CANTARELLA, H.; QUAGGIO, J. A.; FURLANI, A. M. C. Interpretação de resultado de análise de solo. In: RAIJ, B. VAN.; CANTARELLA, H.; QUAGGIO, J. A.; FURLANI, A. M. C. Recomendações de adubação e calagem para o estado de São Paulo. Campinas: IAC, 1997. cap. 4, p. 8-13.

RAIJ, B. VAN; ANDRADE, J. C.; CANTARELLA, H.; QUAGGIO, J. A. Análise química para avaliação da fertilidade de solos tropicais. Campinas: Instituto Agronômico, 2001. $285 \mathrm{p}$.

ROSOLEM, C. A.; SANTOS, F. P.; FOLONI, J. S. S.; CALONEGO, J. C. Potássio no solo em conseqüência da adubação sobre a palha de milheto e chuva simulada. Pesquisa Agropecuária Brasileira, Brasília, v. 41, n. 6, p.1033-1040, 2006.

TOSTA, M. S.; BORGES, F. S. P.; REIS, L. L.; TOSTA, J. S.; M. V.; TOSTA, P. A. F. Avaliação de quatro variedades de alface para cultivo de outono em Cassilândia - MS. Agropecuária Científica no Semi-árido, Campina Grande, v. 5, n. 1, p.30-35, 2009.

TRANI, P. E.; PASSOS, F. A.; AZEVEDO FILHO, J. A. Alface, almeirão, chicória, escarola, rúcula e agrião d água. In: RAIJ, B. VAN.; CANTARELLA, H.; QUAGGIO, J. A.; FURLANI, A. M. C. (Eds.). Recomendações de adubação e calagem para o estado de São Paulo. Campinas: IAC, 1997. cap. 18.6 , p. 168-169.

TRANI, P. E.; RAIJ, B. Hortaliças. In: RAIJ, B. VAN; CANTARELLA, H.; QUAGGIO, J. A.; FURLANI, A. M. C. (Eds.). Recomendações de adubação e calagem para o Estado de São Paulo. Campinas: IAC, 1997. cap. 18.1, p.157-164.

VILLAS BÔAS, R. L.; PASSOS, J. C.; FERNANDES, M.; BÜLL, L. T.; CEZAR, V. R. S.; GOTO, R. Efeito de doses e tipos de compostos orgânicos na produção de alface em dois solos sob ambiente protegido. Horticultura Brasileira, Brasília, v. 22, n. 1, p.28-34, 2004.

WERLE, R.; GARCIA, R. A.; ROSOLEM, C. A. Lixiviação de potássio em função da textura e da disponibilidade do nutriente no solo. Revista Brasileira de Ciência do Solo, Viçosa, v. 32, n. 6, p.2297-2305, 2008.

YURI, J. E.; RESENDE, G. M. DE; MOTA, J. H.; SOUZA, R. J. DE; RODRIGUES JÚNIOR, J. C. Comportamento de cultivares e linhagens de alface americana em Santana da Vargem (MG), nas condições de inverno. Horticultura Brasileira, Brasília, v. 22, n. 2, p.322-325, 2004.

Cultura Agronômica, Ilha Solteira, v.27, n.2, p.217-227, 2018 